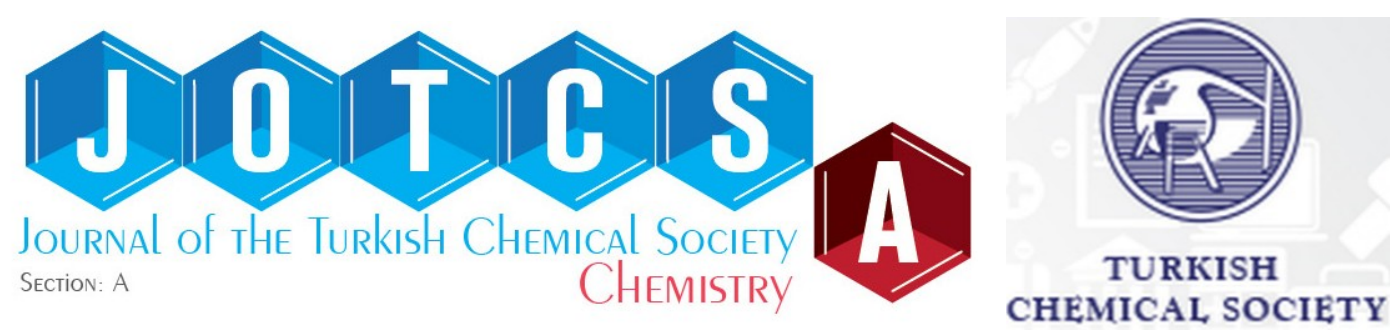

\title{
Polymorphic Phase Change of Calcium Carbonate with Glutamic Acid as an Additive
}

\author{
Sevgi POLAT* $\triangle$, Tuba Nur ÖZALP $\triangle$ D , Perviz SAYAN
}

Marmara University, Department of Chemical Engineering, Istanbul, Turkey

\begin{abstract}
The calcium carbonate $\left(\mathrm{CaCO}_{3}\right)$ crystals were successfully synthesized in the presence of glutamic acid used as an additive at $30{ }^{\circ} \mathrm{C}$ and at a $\mathrm{pH}$ of 8.5. The synthesized product was characterized in detail by X-ray diffraction (XRD), Fourier transform infrared (FTIR) spectroscopy and scanning electron microscopy (SEM) to identify the structure and habit of the crystals. Moreover, the size and surface charge of the crystals were measured by particle size and zeta potential analyzer. XRD and FTIR results showed that both calcite and vaterite in forms of apparently $\mathrm{CaCO}_{3}$ crystals were obtained in the presence of 50 ppm additive concentration at $\mathrm{t}=30 \mathrm{~min}$. When increasing the glutamic acid concentration in the suspension, the formed $\mathrm{CaCO}_{3}$ were only in the vaterite form. The SEM analysis results pointed out that the addition of the glutamic acid significantly changed the shape of the $\mathrm{CaCO}_{3}$. At $\mathrm{t}=30 \mathrm{~min}$ the resulting product sample was found to contain two types of polymorphs; larger cubic shaped calcite crystals and smaller spherical-like vaterite crystals. Further addition of high concentrations of the additive enhanced the adsorption of the glutamic acid, resulting in the smaller spherical-like ellipsoidal vaterite crystals. Investigation of the zeta potential analysis indicated that higher additive concentration $(100 \mathrm{ppm})$ resulted in a positive surface charge of the crystals, whereas lower concentration (50 ppm) gave negative electrical charge. Moreover, filtration analysis pointed out that adding glutamic acid additive resulted in a less specific cake resistance value $\left(5.01 \times 10^{11} \mathrm{~m} / \mathrm{kg}\right)$ than that in pure media, which was $1.03 \times 10^{12} \mathrm{~m} / \mathrm{kg}$.
\end{abstract}

Keywords: Calcium carbonate, polymorphism, crystal morphology, additive.

Submitted: October 16, 2020. Accepted: December 04, 2020.

Cite this: Polat S, Özalp TN, Sayan P. Polymorphic Phase Change of Calcium Carbonate with Glutamic Acid as an Additive. JOTCSA. 2021;8(1):117-24.

DOI: https://doi.org/10.18596/jotcsa.811283.

\section{INTRODUCTION}

There is significant research interest in calcium carbonate $\left(\mathrm{CaCO}_{3}\right)$ because of its industrial importance, diversity as a biomineral, and crystalline complexity $(1,2) \cdot \mathrm{CaCO}_{3}$ typically takes one of three crystal polymorph forms: calcite, aragonite, or vaterite (3). Calcite is the most thermally stable polymorph. The vaterite phase can be converted into the stable calcite phase under appropriate conditions $(4,5)$. The properties of $\mathrm{CaCO}_{3}$ crystals are determined by the crystal polymorph, size, and shape (6). $\mathrm{CaCO}_{3}$ is important in the oil/petrochemicals, water treatment, and energy production. Calcium carbonate is among the most common fillers applied in the pulp and paper industry because of its easy dispersibility and low propensity for agglomeration. Furthermore, $\mathrm{CaCO}_{3}$ particles in the micrometer size range are used in the production of plastics to reinforce polymers, improve their properties, and reduce production costs. In addition, fillers and pigments made using $\mathrm{CaCO}_{3}$ crystals with small particle size have wideranging applications in the pharmaceutical and cosmetics industries, for example, as colorants, abrasives in toothpaste, and coatings for therapeutic delivery (7). Thus, the precise polymorphic and morphological control of $\mathrm{CaCO}_{3}$ crystals is crucial for industrial processes and is the subject of great research interest. Despite being present in small quantities, additives can have a drastic effect on the quality of the final crystalline product (8). Additives influence particular parts of the crystallization process through their close structural relationship 
with the target system. The effects of additives including metal ions (9), carboxylic acids (10), polyelectrolytes (11), biopolymers (12), polysaccharides (13), and amino acids (14) on the phase transformation of $\mathrm{CaCO}_{3}$ have recently been investigated by several research groups. However, to date, the effects of glutamic acid on the $\mathrm{CaCO}_{3}$ transformation process and the morphological and filtration characteristics have not been investigated in detail.

The aim of this study was therefore to investigate the effects of glutamic acid as a crystal modifier on $\mathrm{CaCO}_{3}$ crystal structure, morphology, and size. Glutamic acid is a biodegradable and non-toxic as well as being an effective crystal modifier at low concentrations. In this study, we investigated the effects of glutamic acid on the polymorphic transformation of $\mathrm{CaCO}_{3}$ from calcite to vaterite form, considering the morphology, phase structure, particle size distribution, and filtration characteristics of the end products. The use of glutamic acid as an additive was found to give a significant reduction in the crystal particle size as well as significantly improving the filtration characteristics. The results reported here will be invaluable for ensuring adequate control of product characteristics in industrial processes.

\section{MATERIALS AND METHOD}

\section{Materials}

Calcium chloride dihydrate $\left(\mathrm{CaCl}_{2} \cdot 2 \mathrm{H}_{2} \mathrm{O}\right)$, sodium carbonate $\left(\mathrm{Na}_{2} \mathrm{CO}_{3}\right)$, and glutamic acid $\left(\mathrm{C}_{5} \mathrm{H}_{9} \mathrm{NO}_{4}\right)$ used in the experiment were all analytically pure and were purchased at Merck. All solutions were prepared using distilled water. All experiments were conducted at least in triplicate.

\section{Method}

The polymorphic phase change of $\mathrm{CaCO}_{3}$ was performed using the setup shown in Figure 1 . The synthesis process is as follows. $\mathrm{CaCO}_{3}$ was prepared by the reaction between $\mathrm{CaCl}_{2} \cdot 2 \mathrm{H}_{2} \mathrm{O}$ and $\mathrm{Na}_{2} \mathrm{CO}_{3}$ in $\mathrm{a}$ glass crystallizer with an active volume of $1.0 \mathrm{~L}$ at $30 \pm 0.1^{\circ} \mathrm{C}$.

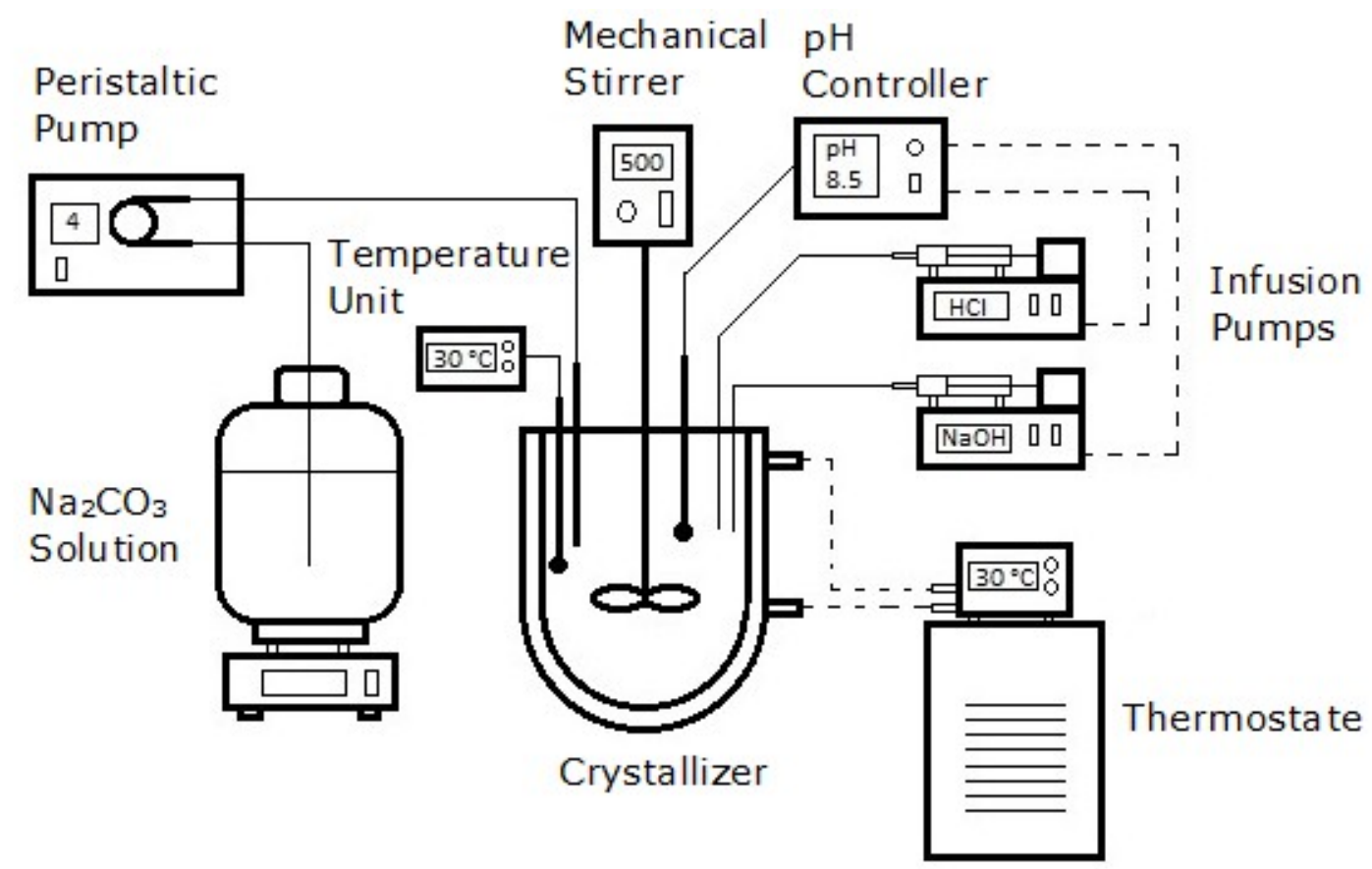

Figure 1. The experimental setup.

At the beginning of the experiment, $0.2 \mathrm{M} \mathrm{CaCl}_{2}$ solution $(400 \mathrm{~mL})$ was placed into the crystallizer. Once the temperature was stabilized, $400 \mathrm{~mL}$ of $\mathrm{Na}_{2} \mathrm{CO}_{3}$ solution with a concentration of $0.2 \mathrm{M}$ was added into the crystallizer at a rate of $4 \mathrm{~mL} / \mathrm{min}$ using a peristaltic pump. The suspension in the crystallizer was stirred at a rate of $500 \mathrm{rpm}$. The $\mathrm{pH}$ value of the suspension was kept at $\mathrm{pH} 8.5$ using 0.1 $\mathrm{N} \mathrm{HCl}(\mathrm{aq})$ and $0.1 \mathrm{~N} \mathrm{NaOH}(\mathrm{aq})$. At 30 and 100 mins, 20-mL aliquots of the suspension were removed and used for crystal structure and morphology analysis.
The influence of glutamic acid and its concentrations on the polymorphic change of $\mathrm{CaCO}_{3}$ was investigated in this study. The specific amount of the glutamic acid (corresponding to $50 \mathrm{ppm}$ and 100 ppm) was added into the crystallizer at the beginning of the experiment. The obtained crystals were filtered by $0.45 \mu \mathrm{m}$ membrane filters connected to a vacuum pump. The crystals were washed thoroughly with distilled water and the remaining crystals were dried at room temperature.

X-ray diffraction (XRD) was used to determine the crystal polymorph of the sample. The XRD pattern of 
the powder sample was collected by a Bruker D2 Phaser Table-top Diffractometer. X-ray radiation $\mathrm{Cu}$ $\mathrm{K} \alpha(\lambda=1.542 \AA)$ was set at $30 \mathrm{kV}$ and $10 \mathrm{~mA}$. Meanwhile, the polymorphic transformation was monitored by Fourier transform infrared spectroscopy (FTIR; Shimadzu IR Affinity-1). The crystal habit and particle size distribution were observed by scanning electron microscopy (SEM; Zeiss EVO LS 10) and Malvern Mastersizer 2000 instrument, respectively. Zeta potential measurements were performed using a Malvern Zeta Sizer Nano Series Nano-ZS.

\section{RESULTS AND DISCUSSION}

\section{XRD Analysis}

Figure 2 illustrates the XRD patterns of $\mathrm{CaCO}_{3}$ crystals with and without glutamic acid in which $\mathrm{C}$ represents peaks from calcite, while $\mathrm{V}$ denotes peaks from vaterite within the range of $10-70^{\circ}$.
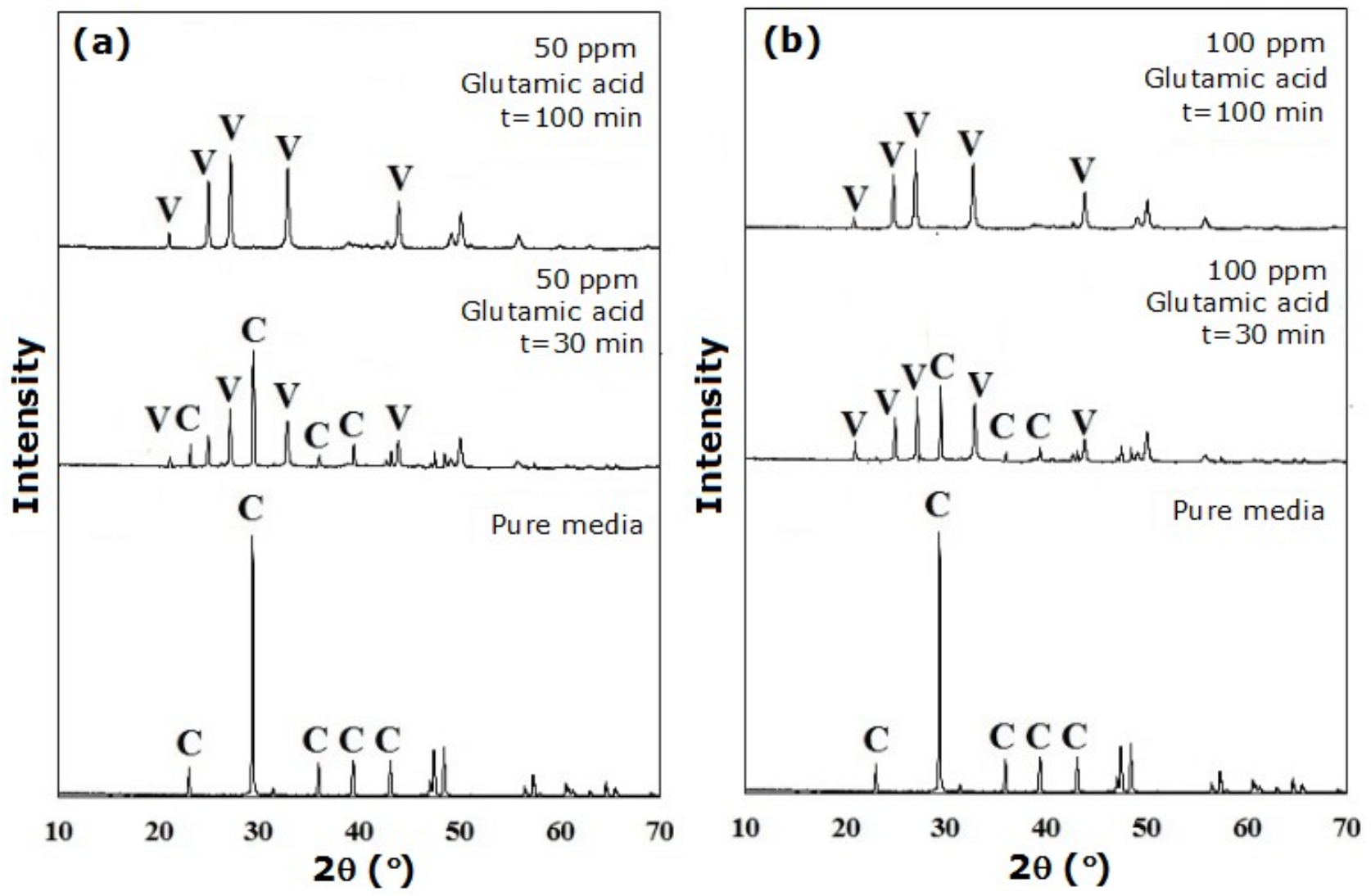

Figure 2. XRD patterns for $\mathrm{CaCO}_{3}$ crystals acquired in pure media and media supplemented with 50 ppm (a) and 100 ppm (b) glutamic acid.

XRD patterns of the crystals acquired in pure media showed that calcite was the only major crystallization product. All the main characteristic peaks of the crystal products with corresponding faces (012), (104), (110), (113) and (022) were the standard pattern of calcite form (JCPDS: 05-0586). The addition of glutamic acid to the solution led to significant changes in crystal structure and new crystallization products were formed. In addition to the characteristic diffraction peaks of calcite, the new diffraction peaks of vaterite were detected at $2 \theta=21.0^{\circ}, 24.9^{\circ}, 27.1^{\circ}, 32.7^{\circ}$, and $50.1^{\circ}$ (JCPDS: 33-0268). For the solid sample obtained at $30 \mathrm{~min}$, the characteristics peaks of both calcite and vaterite were seen together. As time goes by, the characteristic peak intensity of vaterite enhanced, while that of the calcite weaken. At $t=100 \mathrm{~min}$, the calcite peaks disappeared completely and the vaterite was the only crystallization product at each characteristic point of the system. The XRD results showed that glutamic acid altered the crystal form of $\mathrm{CaCO}_{3}$.

\section{FTIR Analysis}

The calcite and vaterite polymorphs could be distinguished according to FTIR spectra. The spectra of calcite and vaterite are obviously different. Thus, except for XRD analysis, FTIR analysis was performed to follow the polymorphic phase transformation of $\mathrm{CaCO}_{3}$. The FTIR spectra for $\mathrm{CaCO}_{3}$ crystals with and without glutamic acid are given in Figure 3. 

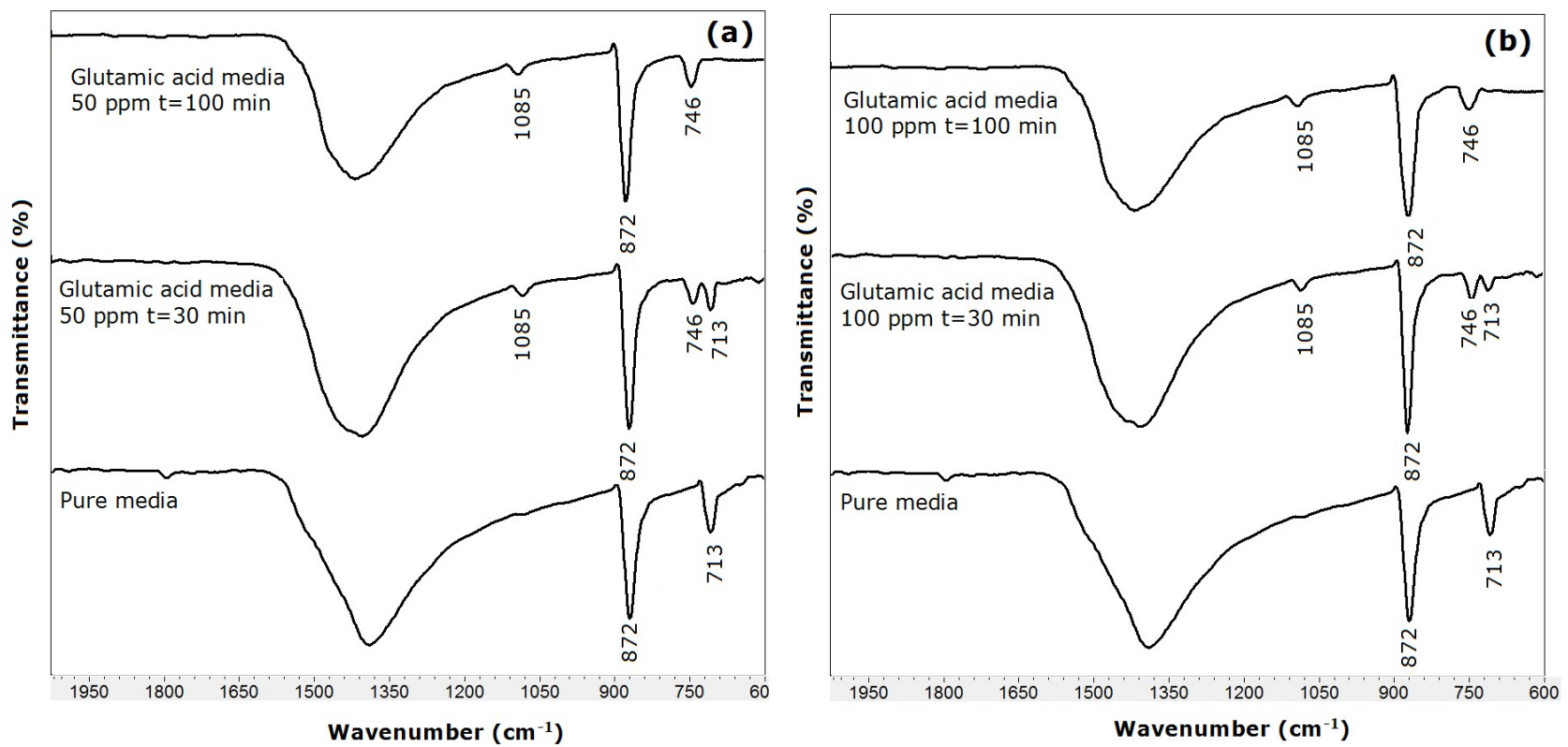

Figure 3. FTIR results for $\mathrm{CaCO}_{3}$ crystals acquired in pure media and media supplemented with 50 ppm (a) and $100 \mathrm{ppm}$ (b) glutamic acid.

The FTIR spectrum of the $\mathrm{CaCO}_{3}$ crystals acquired in pure media is very similar in the intensity and position of the main characteristic absorption peak $\left(712 \mathrm{~cm}^{-1}\right)$ with that of calcite form reported by the previous studies (15-17). When the FTIR spectra for the crystals with 50 and 100 ppm glutamic acid at 30 min were examined, new additional absorption bands not in the spectrum of the crystals acquired in pure media were detected at $1085 \mathrm{~cm}^{-1}$ and $746 \mathrm{~cm}^{-1}$ belonged to the vaterite polymorph. The crystal products acquired in the presence of $50 \mathrm{ppm}$ additive concentration were mixtures of calcite and vaterite, and the intensity of the calcite peaks was weaker than the intensity of the vaterite peaks. At higher additive concentration, intensity of the peaks of the calcite was very weak while the corresponding main absorption peak of vaterite was very strong. FTIR spectra for the crystals acquired at $\mathrm{t}=100 \mathrm{~min}$ showed that the crystal products were all vaterite purely. These results are supported by the XRD patterns.

\section{SEM Analysis}

SEM analysis was conducted to explore the effect of glutamic acid and its concentration on the surface character of $\mathrm{CaCO}_{3}$ crystals. The $\mathrm{CaCO}_{3}$ crystals acquired in pure media consisted mainly of smooth and uniform cubic-shaped calcite crystals with the mean particle size of $32.0 \mu \mathrm{m}$ as shown in Figure $4 \mathrm{a}$. The similar morphology of $\mathrm{CaCO}_{3}$ crystals was observed in the recent studies $(18,19)$. 

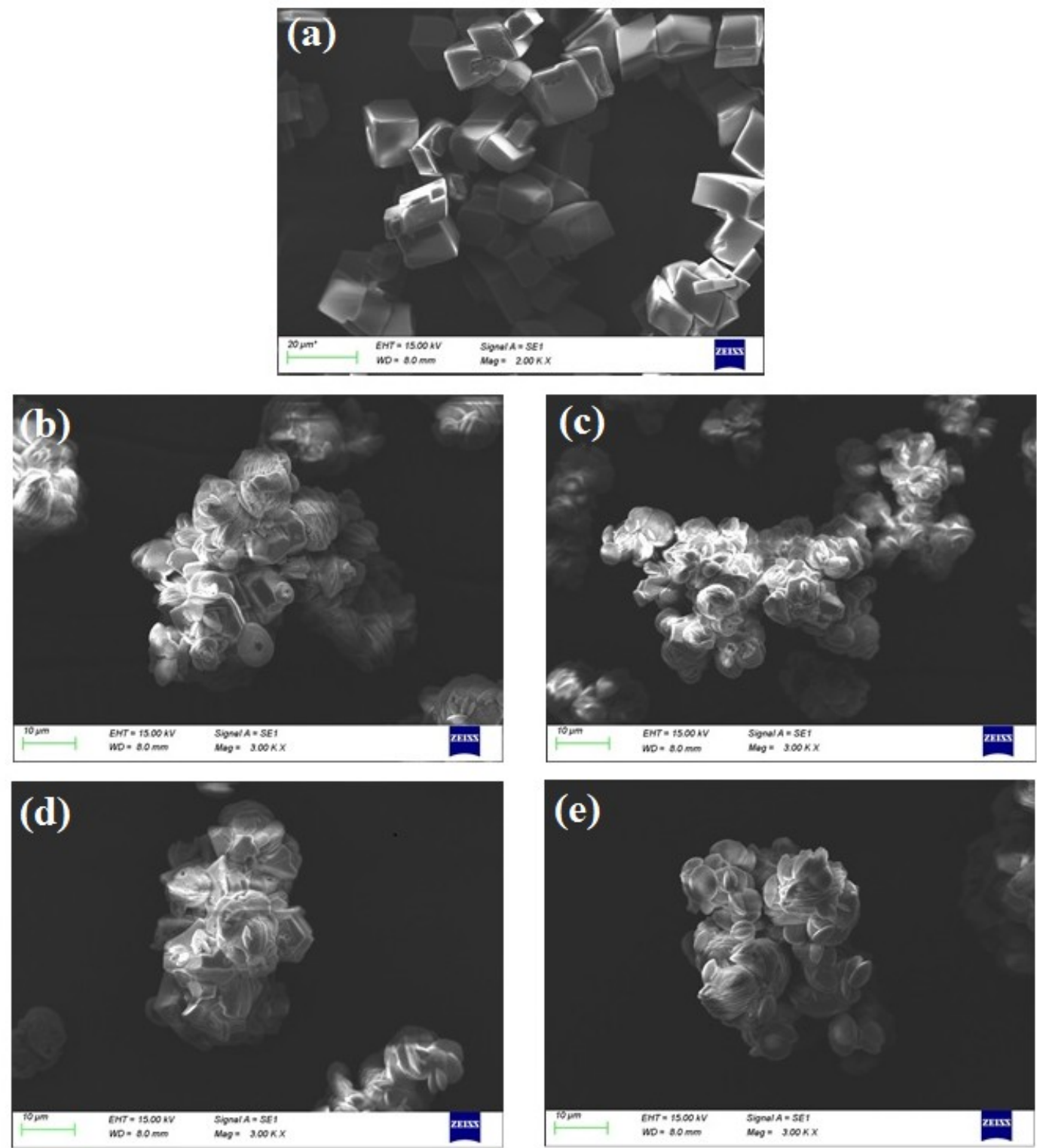

Figure 4. SEM images for $\mathrm{CaCO}_{3}$ crystals acquired in pure media (a) and media supplemented with 50 ppm glutamic acid at $\mathrm{t}=30 \mathrm{~min}$ (b) and at $\mathrm{t}=100 \mathrm{~min}$ (c) and with $100 \mathrm{ppm}$ glutamic acid at $\mathrm{t}=30 \mathrm{~min}(\mathrm{~d})$ and at $\mathrm{t}=100 \mathrm{~min}(\mathrm{e})$.

As can be seen from Figure $4(b-d)$, the morphological characteristics of the $\mathrm{CaCO}_{3}$ crystals were directly related to the transformation time and glutamic acid concentration. Examining the SEM image of the crystals with 50 ppm glutamic acid at 30 min (Figure 4b), the cubic-shaped calcite crystals started to change. Alongside the cubic calcite crystals, vaterite crystals with a round appearance started to form. The formed crystals consisted of highly robust agglomerates. As the transformation process continued, the cubic calcite crystals were no longer formed, and all of the crystals were sphericallike vaterite crystals with the rough surface aggregated by many particles (Figure 4c). Moreover, there was a significant increment in the counts of small particles. When the SEM image of the crystal products acquired with $100 \mathrm{ppm}$ additive at $30 \mathrm{~min}$
(Figure 4d) was examined, it was determined that there was more transformation of calcite into vaterite crystals in comparison to the concentration of $50 \mathrm{ppm}$. However, the two polymorphs were still found together in the same medium, and the obtained crystals had an irregular shape, and some of the crystals formed irregular aggregates. The vaterite crystals grown on the surfaces of the untransformed calcite crystals were in an ellipsoidal form with a plate structure. As the transformation process progressed, the calcite crystals completely transformed to the vaterite and gained a spherical and ellipsoidal appearance (Figure 4e). The surface of the crystals was rough and included a lot of spherical-like particles aggregated. It was also detected that the mean particle size of the final products was smaller in comparison to both pure 
and $50 \mathrm{ppm}$ additive media. As shown in Figure 5, the mean particle size of $\mathrm{CaCO}_{3}$ decreased from 17.9 to $14.6 \mu \mathrm{m}$ as the glutamic acid concentration increased from 50 to $100 \mathrm{ppm}$. It can be concluded that the glutamic acid had a profound effect on the controlling the polymorph, habit, and particle size of the crystals due to its adsorption on the active site of $\mathrm{CaCO}_{3}$.
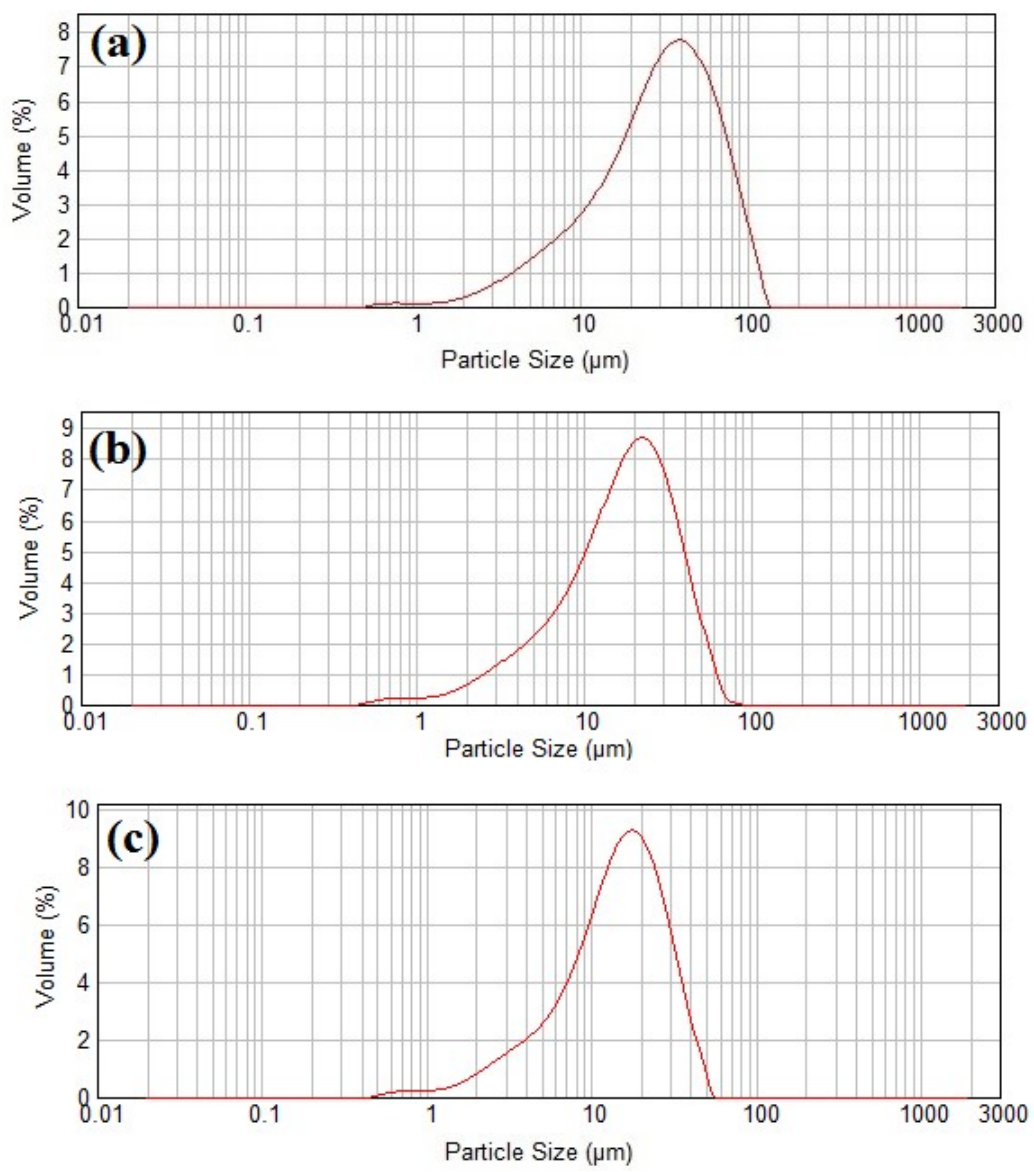

Figure 5. Particle size distributions for $\mathrm{CaCO}_{3}$ crystals acquired in pure media (a) and media supplemented with 50 ppm glutamic acid (b) and with 100 ppm glutamic acid (c) at $\mathrm{t}=100 \mathrm{~min}$.

\section{Zeta Potential Analysis}

The zeta potential of the $\mathrm{CaCO}_{3}$ crystals with and without glutamic acid was investigated to determine the surface charge of the samples. The results are given in Figure 6 . The zeta potential of $\mathrm{CaCO}_{3}$ crystals acquired in pure media was $-8.1 \pm 2.1 \mathrm{mV}$. 


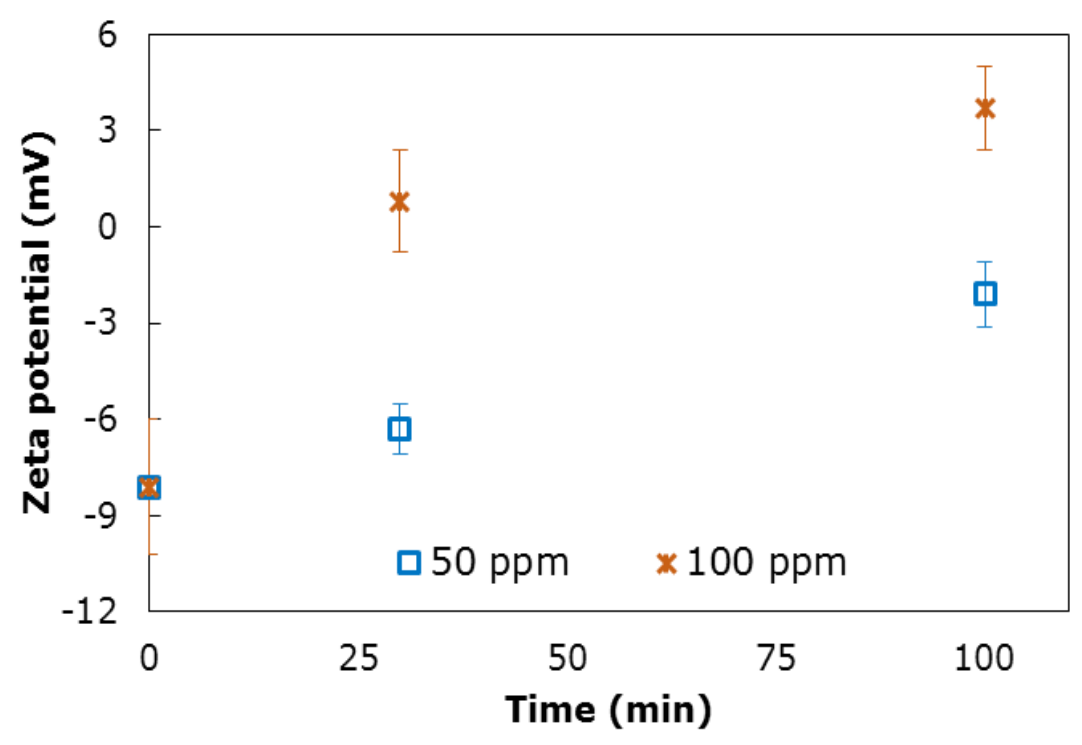

Figure 6. The change of zeta potential with time.

The addition of glutamic acid to the crystallization media led to a distinctive change in surface charge and the zeta potential value at $50 \mathrm{ppm}$ reached -6.3 \pm 0.8 and $-2.1 \pm 1.0 \mathrm{mV}$ for $\mathrm{t}=30$ and $100 \mathrm{mins}$, respectively. The zeta potential value of $\mathrm{CaCO}_{3}$ crystals acquired in 100 ppm additive media showed a rising tendency and the electrical surface charge was more positive.

\section{Filtration Analysis}

Filtration characteristics of $\mathrm{CaCO}_{3}$ is important for economic considerations, since this characteristic is closely related with energy consumption during the filtration process. Therefore, the filtration property of the $\mathrm{CaCO}_{3}$ crystals with and without additive was evaluated by Darcy's Law under 700 mbar constant pressure. The average specific cake resistance and the average cake porosity of the $\mathrm{CaCO}_{3}$ crystals acquired without glutamic acid were $1.03 \times 10^{12} \mathrm{~m} / \mathrm{kg}$ and 0.548 , respectively.

When 50 ppm glutamic acid was added to the crystallization media, the average specific cake resistance decreased to $8.26 \times 10^{11} \mathrm{~m} / \mathrm{kg}$. Increasing the additive concentration to $100 \mathrm{ppm}$ caused to significantly reduce the effect on the specific cake resistance $\left(5.01 \times 10^{11} \mathrm{~m} / \mathrm{kg}\right)$. This decreasing trend in specific cake resistance can be explained by the changes in the morphology and particle size of the $\mathrm{CaCO}_{3}$ crystals. In the same time, the average cake porosity increased from 0.589 to 0.703 as the glutamic acid concentration increased from 50 to 100 ppm. Glutamic acid exhibited good performance in promoting the acceleration of filtration and improving the filtration properties of the $\mathrm{CaCO}_{3}$ crystals.

\section{CONCLUSION}

The present study investigated the effect of the glutamic acid on the polymorphic change of $\mathrm{CaCO}_{3}$. Specific conclusions drawn from this work include the following:

- The XRD and FTIR results showed that although a calcite structure was created in pure media, a vaterite structure was produced in the presence of glutamic acid.

- According to the SEM and particle size analysis, the additive significantly reduced the size of the crystal and changed its morphology. The mean size of the crystals decreased from 32.0 to $14.6 \mu \mathrm{m}$ with the use of the additive. It can be suggested that glutamic acid could be used as a crystal size and morphology modifier.

- The results of the zeta potential measurement suggested that glutamic acid increased the positivity of the surface charge of the $\mathrm{CaCO}_{3}$ crystals.

- $\quad$ The values of the average specific cake resistance were calculated in the range of $1.03 \times 10^{12}$ to $5.01 \times 10^{11} \mathrm{~m} / \mathrm{kg}$.

- It can be concluded that glutamic acid is important for better understanding and controlling the polymorph, size, and morphology of $\mathrm{CaCO}_{3}$ crystals.

\section{ACKNOWLEDGMENT}

Authors would like to acknowledge the Marmara University Scientific Research Projects Commission for financial support. (Project number: FYL-202010025)

\section{REFERENCES}

1. Zhao Z, Zhang L, Dai H, Du Y, Meng $X$, 
Zhang $\mathrm{R}$, et al. Surfactant-assisted solvo- or hydrothermal fabrication and characterization of high-surface-area porous calcium carbonate with multiple morphologies. Microporous Mesoporous Mater. 2011;138:191-199.

2. Butler MF, Frith WJ, Rawlins C, Weaver AC, Heppenstall-Butler M. Hollow calcium carbonate microsphere formation in the presence of biopolymers and additives. Cryst Growth Des. 2009;9:534-545.

3. Koga N, Kasahara D, Kimura T. Aragonite crystal growth and solid-state aragonite-calcite transformation: A physico-geometrical relationship via thermal dehydration of included water. Cryst Growth Des. 2013;13:2238-2246.

4. Zhang J, Zhou $X$, Dong $C$, Sun $Y, Y u$ J. Investigation of amorphous calcium carbonate's formation under high concentration of magnesium: The prenucleation cluster pathway. J Cryst Growth. 2018;494:8-16.

5. Trushina DB, Bukreeva T V., Kovalchuk M V., Antipina $\mathrm{MN}$. $\mathrm{CaCO} 3$ vaterite microparticles for biomedical and personal care applications. Mater Sci Eng C. 2014;45:644-658.

6. Saulat $H$, Cao $M$, Khan $M M$, Khan $M$, Khan MM, Rehman A. Preparation and applications of calcium carbonate whisker with a special focus on construction materials. Constr. Build. Mater. 2020;236:117613.

7. Aghajanian S, Koiranen T. Dynamic modeling and semibatch reactive crystallization of calcium carbonate through $\mathrm{CO} 2$ capture in highly alkaline water. J CO2 Util. 2020;38:366-374.

8. Ševčík R, Pérez-Estébanez $M$, Viani $A$, Šašek $P$, Mácová $P$. Characterization of vaterite synthesized at various temperatures and stirring velocities without use of additives. Powder Technol. 2015; 284:265-271.

9. Jung GY, Shin E, Park JH, Choi BY, Lee SW, Kwak SK. Thermodynamic Control of Amorphous Precursor Phases for Calcium Carbonate via Additive Ions. Chem Mater. 2019; 31:7547-7557.

10. Miyashita M, Yamada E, Kawano M. Influence of low-molecular-weight dicarboxylic acids on the formation of calcium carbonate minerals in solutions with Mg2+ ions. J Mineral Petrol Sci. 2018; 113:207217.

11. Wang $\mathrm{T}$, Cölfen $\mathrm{H}$, Antonietti M. Nonclassical crystallization: Mesocrystals and morphology change of $\mathrm{CaCO} 3$ crystals in the presence of a polyelectrolyte additive. J Am Chem Soc. 2005; 127:3246-3247.

12. Kirboga S, Oner M, Akyol E. The effect of ultrasonication on calcium carbonate crystallization in the presence of biopolymer. J Cryst Growth. 2014; 401:266-270.

13. Yang L, Zhang X, Liao Z, Guo Y, Hu Z, Cao Y. Interfacial molecular recognition between polysaccharides and calcium carbonate during crystallization. J Inorg Biochem. 2003; 97:377-383.

14. Yao $Y$, Dong W, Zhu S, Yu X, Yan D. Novel morphology of calcium carbonate controlled by poly(L-lysine). Langmuir. 2009; 25:13238-13243.

15. Zheng $\mathrm{T}$, Zhang X, Yi H. Spherical vaterite microspheres of calcium carbonate synthesized with poly (acrylic acid) and sodium dodecyl benzene sulfonate. J Cryst Growth. 2019; 528:125275.

16. Wei $Y, X u H, X u S, S u H$, Sun $R$, Huang $D$, et al. Synthesis and characterization of calcium carbonate on three kinds of microbial cells templates. J Cryst Growth. 2020;547:125755.

17. Abeywardena MR, Elkaduwe RKWHMK, Karunarathne DGGP, Pitawala HMTGA, Rajapakse RMG, Manipura $A$, et al. Surfactant assisted synthesis of precipitated calcium carbonate nanoparticles using dolomite: Effect of $\mathrm{pH}$ on morphology and particle size. Adv Powder Technol. 2020;31:269-278.

18. Zheng T, Yi H, Zhang S, Wang C. Preparation and formation mechanism of calcium carbonate hollow microspheres. J Cryst Growth. 2020; 549:125870.

19. Fujiwara M, Shiokawa K, Kubota T, Morigaki $\mathrm{K}$. Preparation of calcium carbonate microparticles containing organic fluorescent molecules from vaterite. Adv Powder Technol. 2014; 25:1147-1154. 